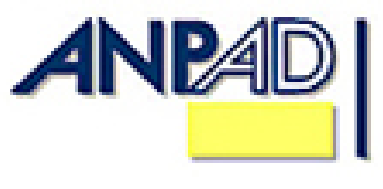

\author{
Disponível em \\ http://www.anpad.org.br/rac \\ RAC, Rio de Janeiro, v. 19, n. 4, art. 6, \\ pp. 525-543, Jul./Ago. 2015 \\ http://dx.doi.org/10.1590/1982-7849rac20151951 \\ $(\infty \mathrm{c}) \mathrm{EY}-\mathrm{NC}$
}

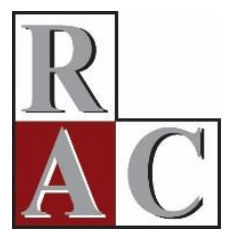

\title{
História de Vida e Trajetórias Profissionais: Estudo com Executivos Brasileiros
}

Life History and Career Paths: A Study of Brazilian Executives

Lisiane Quadrado Closs Universidade Federal do Rio Grande do Sul - UFRGS

Sidinei Rocha-de-Oliveira Universidade Federal do Rio Grande do Sul - UFRGS 


\title{
Resumo
}

A noção de carreira tem, por natureza, uma constituição interdisciplinar, congregando a visão do indivíduo, da organização e da sociedade. Entretanto, apesar dos avanços nas discussões sobre o tema, estudos recentes revelam limites das teorias utilizadas, conclamando a necessidade de maior interdisciplinaridade (Arthur, 2008; Chudzikowski \& Mayrhofer, 2011; Khapova \& Arthur, 2011; Lawrence, 2011). Visando contribuir para a interdisciplinaridade nos estudos de carreira, o presente artigo tem como objetivo apresentar e ilustrar o potencial do uso de histórias de vida analisando as influências e os limites às trajetórias profissionais de sete executivos brasileiros por meio desse método. Os resultados são apresentados em duas grandes categorias de análise: (a) influências do contexto nas carreiras, envolvendo: mudanças no cenário econômico e organizacional brasileiro, maior concorrência e necessidade de aprofundar conhecimentos em face à globalização, demanda por mobilidade, e discriminação de gênero; (b) momentos da vida e escolhas profissionais, incluídos aspectos individuais das trajetórias, tais como: valores da família, escolha do curso de graduação, ingresso no mercado de trabalho e nascimento dos filhos.

Palavras-chave: carreira; trajetórias profissionais; história de vida.

\begin{abstract}
The notion of what constitutes a career is interdisciplinary by nature, congregating views from an individual, organizations and society. Nevertheless, despite progress in discussions on the subject, recent studies have pointed towards the limitations of currently used theories, calling for greater interdisciplinarity (Arthur, 2008; Chudzikowski \& Mayrhofer, 2011; Khapova \& Arthur, 2011; Lawrence, 2011), since little evolution has occurred in this sense. In order to respond to the need for multidisciplinary research in career studies, this paper aims to present and illustrate the potential use of life histories by analyzing the influences and limits on seven Brazilian executives' career paths through this method. Results are presented in two broad categories of analysis: (a) contextual influences on careers involving changes in the Brazilian economic and organizational setting, increased competition and need to increase knowledge in face of globalization, mobility demand and gender discrimination; (b) life stages and career choices, including individual aspects of their trajectories, such as family values, choice of undergraduate courses, entering the labor market and parenthood.
\end{abstract}

Key words: career; professional trajectories; life history. 


\section{Introdução}

A noção de carreira é interdisciplinar por natureza (Arthur, Hall, \& Lawrence, 1989; Moore, Gunz, \& Hall, 2007), integrando os pontos de vista do indivíduo (sentidos do trabalho, vocação, motivação para o trabalho, expectativas profissionais), da organização (necessidade de aquisição, desenvolvimento e retenção de talentos para manter-se e desenvolver-se frente à concorrência) e da sociedade (mercado de trabalho, status da profissão). Tais perspectivas são, historicamente, tratadas por áreas distintas nos estudos sobre carreiras, gerando conhecimentos fragmentados sobre o tema (Khapova \& Arthur, 2011). Assim, apesar dos avanços nas discussões sobre o assunto, estudos recentes têm apontado para as limitações das teorias em uso, apelando para uma maior interdisciplinaridade nesse campo teórico (Arthur, 2008; Chudzikowski \& Mayrhofer, 2011; Khapova \& Arthur, 2011; Lawrence, 2011; Van Maanen, 2015).

Considerando que a renovação de um campo de pesquisa deve buscar a inovação, tanto na sua discussão teórica quanto em seus métodos e posicionamento epistemológico, o presente artigo tem como objetivo apresentar e ilustrar o potencial do uso de histórias de vida, analisando as influências e os limites às trajetórias profissionais de sete executivos brasileiros por meio desse método. Desta forma, ao voltar-se para a discussão interdisciplinar dos estudos de carreira, a contribuição deste trabalho para essa literatura é dupla. Em primeiro lugar, apresenta-se a pesquisa de história de vida, cuja aplicação ainda é escassa em estudos no campo da Administração no Brasil (Closs \& Antonello, 2011), como uma abordagem metodológica que permite tratar alguns dos desafios envolvidos no estudo de carreira dos trabalhadores contemporâneos em diferentes contextos sociais. Em segundo lugar, apresenta-se uma pesquisa com sete executivos brasileiros que explora as influências de mudanças ocorridas no contexto brasileiro, bem como dos momentos de vida e das escolhas profissionais nas carreiras desses gestores, apontando limites à carreira que alguns desses elementos representam.

$\mathrm{O}$ artigo se organiza da seguinte forma: primeiramente, apresenta-se o debate que vem ocorrendo sobre a necessidade de interdisciplinaridade na literatura sobre carreira. Na segunda seção, explora-se a história de vida como abordagem para a pesquisa, destacando os seus pontos fortes e suas limitações para os estudos sobre carreiras. A seguir, a partir de um estudo realizado entre gestores brasileiros utilizando história de vida, busca-se analisar suas trajetórias de carreiras sob perspectivas de análises interdisciplinares. Na discussão, detalham-se as contribuições propiciadas pelo uso do método de história de vida e destacam-se a importância de buscar novas formas de coleta e análise de dados como maneira de promover a interdisciplinaridade nos estudos sobre carreira. Por último, tecem-se as considerações finais do estudo.

\section{Estudos de Carreira: em Busca da Interdisciplinaridade}

Na década de 1990, dois estudos marcam o início de uma nova era da discussão teórica sobre carreira: Arthur e Rosseau (1996), com o seu conceito de carreira sem fronteiras, e Hall (1996), com o de carreira proteana. Nos anos que se seguiram, as discussões em torno desses dois conceitos predominaram, assim como sucessivas tentativas de construir modelos que pudessem prová-los com maior eficiência (Khapova \& Arthur, 2011; Sullivan \& Baruch, 2009). No entanto, segundo Sullivan e Baruch (2009), esses estudos priorizam abordagens quantitativas e pontos de vista do indivíduo, deixando a interdisciplinaridade em segundo plano.

Com o objetivo de promover a discussão em direção a abordagens interdisciplinares, Khapova e Arthur (2011) destacam diferentes perspectivas sociais para o estudo das carreiras: (a) psicológicas: interessa-se por compreender como as diferenças individuais, as necessidades e as capacidades adaptativas influenciam as carreiras; (b) sociológicas: enfoca como os indivíduos são moldados pelos grupos sociais em que são socializados e como as ações cotidianas das pessoas reforçam e reproduzem 
estruturas sociais; (c) sociopsicológicas: questiona como os pensamentos, sentimentos e comportamentos das pessoas são influenciados pela presença de outros e como estruturas e processos sociais influenciam os indivíduos e grupos; (d) econômicas: centra-se no trabalho físico e mental usado para produzir bens e serviços, em conhecimentos e habilidades que permitam às pessoas produzir, e em carreiras empreendedoras.

Essas diferentes perspectivas também são apresentadas por Moore, Gunz e Hall (2007), que buscam fazer um resgate histórico das noções de carreira apontando autores clássicos na sociologia e na psicologia que abordem a temática, indiretamente, em sua proposta teórica. Os autores mostram que a noção de carreira apresenta uma tensão constante entre aspectos sociais e individuais, focados nas perspectivas social ou psicológica.

Uma vez que cada uma dessas áreas do conhecimento utiliza os seus próprios conceitos, construções teóricas, posicionamentos epistemológicos e modos de coleta e análise de dados, a interdisciplinaridade nesse campo teórico fica limitada. Assim, Chudzikowski e Mayrhofer (2011) enfatizam a importância do uso de referenciais teóricos que favoreçam a integração e a busca de diálogos construtivos e críticas entre diferentes - e, às vezes, conflitantes - pontos de vista sociais em que as discussões sobre carreiras se inserem, conjugando múltiplas perspectivas.

A busca por uma proposta interdisciplinar para estudos sobre carreiras também está explícita no compêndio de quatro volumes sobre o tema organizado por Inkson e Savickas (2012). Os autores buscam apresentar nesta obra as diferentes teorias que marcam os estudos sobre carreiras (Desenvolvimento Vocacional, Carreira e Profissão, Identidade e Organização, Sucesso Profissional, para citar apenas alguns) considerando a contribuição de diferentes campos de conhecimento, como a psicologia, marcada pelos trabalhos voltados para a escolha profissional, e a sociologia, com a maior contribuição vinda de Parsons e da Escola de Chicago. Arthur (2012) encerra a obra, destacando que as diferentes tradições dos estudos sobre carreira ainda encontram-se fragmentadas, sendo necessário um esforço de estudos empíricos como forma de explorar as potencialidades de ligação das diferentes perspectivas teóricas. Uma investigação que contempla vários níveis de análise, envolvendo perspectivas de indivíduos e de organizações em contextos distintos, pode ampliar a compreensão das trajetórias profissionais de trabalhadores contemporâneos. Tal investigação também permite analisar os limites que emergem nas construções de carreira em maior profundidade (Inkson, Gunz, Ganesh, \& Roper, 2012). Assim, propicia a exploração dos limites profissionais, internos e externos à pessoa (Chudzikowski \& Mayrhofer, 2011), além das fronteiras como construções sociais (Inkson et al., 2012).

Ituma e Simpson (2009) apresenta resultados ricos por meio da utilização de uma pesquisa qualitativa explorando a natureza dos limites de carreira na Nigéria, com enfoque no contexto, perspectiva que tem sido negligenciada na teoria sobre o tema. $\mathrm{O}$ estudo contribui para o debate sobre $\mathrm{o}$ predomínio do modelo de carreiras sem fronteiras, sugerindo que este modelo de carreira tem sido utilizado de modo exagerado e que este pode refletir apenas um modelo anglo-saxão de trajetória profissional. $\mathrm{O}$ autor defende que os limites de carreira ainda existem, mesmo em um contexto que tenha sido previamente pensado para ser fluido e caracterizado pela mobilidade de carreira porque essas fronteiras são, em grande parte, dependentes do contexto.

A dinâmica do tempo nas carreiras envolve diferentes visões. Sob a ótica do indivíduo, é possível vincular a carreira com o curso de vida; já na sociologia, prevalece a visão das limitações externas, tais como as impostas pelo mercado de trabalho. Essa análise integrada de diferentes níveis entre indivíduo e contexto estimula a interdisciplinaridade e permite avanços nos estudos sobre carreira (Chudzikowski \& Mayrhofer, 2011).

Inkson, Gunz, Ganesh e Roper (2012), ao destacarem o aspecto social da formação das fronteiras, apontam os sujeitos como corresponsáveis pela construção desses limites de carreira, sendo de grande importância compreender como as pessoas os formam internamente. Assim, torna-se relevante analisar porque um ator não escolheu muitas das possibilidades disponíveis, bem como analisar o processo de escolha de sua trajetória. Outro caminho que pode ser explorado relaciona as organizações e as profissões com a formação de carreiras, analisando como mudanças econômicas e tecnológicas levam à 
extinção de antigas profissões e ao surgimento de novas, além de analisar como essas mudanças são incorporadas pelos indivíduos.

Segundo Inkson et al. (2012), em um dado momento de vida, cada sujeito tem muitas alternativas de carreira, representando possíveis trajetórias a serem assumidas. No entanto, tais possibilidades podem ser limitadas, parcial ou totalmente, dependendo da posição social em que o sujeito se encontra. Assim, torna-se importante analisar porque um sujeito deixou de escolher algumas trajetórias entre as diversas que eram possíveis, identificando os limites que se impuseram interna e externamente durante suas escolhas profissionais.

Além disso, a compreensão de carreira não está relacionada apenas com os sujeitos, elas representam organizações e profissões, bem como as relações das mesmas com as trajetórias profissionais. Assim, cada novo ciclo de transformações tecnológicas e de ocupações/profissões que surgem modificam-se e deixam de existir, trazem significativos reflexos sobre as carreiras individuais. É necessário o aprendizado de uma nova realidade e a adequação a uma nova forma de agir profissional.

Como se observa, a integração de distintas disciplinas acadêmicas possibilita um novo horizonte para as pesquisas sobre carreira, ampliando a compreensão sobre como as fronteiras são construídas e como é sua dinâmica entre o indivíduo e a estrutura social, destacando-se aspectos relacionados com a esfera do trabalho, com o mercado e com a profissão. A fim de realizar estudos que contemplem essas perspectivas, no entanto, é necessário procurar abordagens metodológicas capazes de estabelecer ligações para torná-los possíveis. A seção seguinte discute o potencial da abordagem de história de vida para o alcance desse objetivo.

\section{História de Vida}

Neste estudo, a história de vida é entendida como uma estratégia de pesquisa que integra a abordagem biográfica (Denzin, 1989). Trata-se de um registro escrito, com base em narrativas pessoais, coletado por meio de entrevistas (Atkinson, 2002). O que diferencia este método é a contextualização pessoal, histórica, social, institucional e/ou política de narrativas (Delory-Momberger, 2012; Denzin, 1989), revelando ações e emoções, bem como interações entre pessoas e eventos (Xing \& Sims, 2012), procurando desvendar essas forças que moldam, distorcem e alteram experiências vividas (Bertaux, 1993; Hatch \& Wisniewski, 1995).

As histórias de vida permitem compreender as experiências biográficas em sua relação com a sociedade, a cultura e a instituições criadoras de significados de modo mais amplo (Delory-Momberger, 2012; Denzin, 1989). As entrevistas de história de vida possibilitam que os respondentes estabeleçam para si próprios suas motivações, valores e escolhas de carreira, configuradas nos seus mundos sociais e profissionais (Smith, 2012). Essa peculiaridade remete à interseção das perspectivas psicológica e social na pesquisa sobre carreira, uma vez que envolve pessoas com vocações, motivações e expectativas aparentemente únicas, mas que são profundamente influenciadas pela interação com o seu meio ambiente e sua coletividade (Delory-Momberger, 2012). Enfocada em termos das teorias de agência e estrutura, Smith (2012) observa que estas estão entrelaçadas, e que a estrutura restringe, mas também possibilita a agência. A força das histórias de vida e das narrativas encontra-se "na dialética entre as experiências únicas dos indivíduos e as limitações das amplas estruturas sociais, políticas e econômicas" (Hatch \& Wisniewski, 1995, p. 128). Vislumbra-se a possibilidade da abordagem de história de vida auxiliar na compreensão de aspectos objetivos - como dados do contexto econômico, político, histórico e social - e subjetivos, a exemplo de papel do espaço, do tempo e das emoções, resultando em construções sociais e de sentido, inerentes a indivíduos e coletividades situados em contextos organizacionais específicos. Assim, o acesso às diversas dimensões da vida humana permitidos por esta estratégia metodológica pode favorecer uma visão interdisciplinar das carreiras contemporâneas, enriquecendo investigações sobre o tema e ampliando a sua compreensão. 
Recentemente Peticca-Harris e McKenna (2013) e Van Maanen (2015) evidenciam como as histórias de vida podem contribuir para aprofundar as discussões sobre carreira ao explorar as relações entre a experiência vivenciada pelo sujeito da pesquisa, identidade profissional e as mudanças de contexto no desenvolvimento de sua carreira. Peticca-Harris e McKenna (2013) tomaram por base apenas uma gestora, situando sua carreira e suas escolhas particulares em relação aos contextos profissional, social e cultural vivenciados por ela, mas igualmente sobre a trajetória de carreira de outros profissionais, influenciados pelas mesmas regras desses contextos. Van Maanen (2015) segue as bases de um estudo etnográfico para construir a narrativa da sua própria trajetória como docente, destacando as contribuições para a compreensão de como se constroem as carreiras de pesquisadores e como ocorre a relação entre organização e indivíduos nessa profissão.

A seguir, descrevem-se os procedimentos metodológicos adotados na pesquisa realizada sob a abordagem de história de vida apresentada no atual estudo.

\section{Procedimentos metodológicos da pesquisa utilizando história de vida}

Um aspecto comum entre as pesquisas envolvendo narrativas é o reduzido número de participantes (Chase, 2005; Riessman, 2005), já que uma única história de vida pode revelar comportamentos e técnicas, valores e ideologias, entre outros aspectos importantes de sua sociedade ou grupo (Delory-Momberger, 2012). Verifica-se na literatura científica desde estudos baseados em apenas uma história de vida a trabalhos que contemplam 800 casos, havendo grande variação no número de casos investigados sob essa abordagem metodológica (Bertaux \& Kohli, 1984; Nóvoa, 1995).

Como a abordagem de pesquisa adotada demanda tempo e dedicação, tanto dos participantes como dos pesquisadores, não é recomendada para estudos com grande número de entrevistados (Riessman, 2005). Assim, limitou-se a sete o número de entrevistados, pois, seguindo o critério de saturação, esse grupo de participantes propiciou suficiente riqueza de dados para análise e para a consecução dos objetivos propostos pelo estudo. Os pesquisados foram executivos de ambos os gêneros, egressos de programas de Master in Business Administration (MBA) de universidades brasileiras e estrangeiras, com pelo menos dois anos de experiência profissional em cargos executivos, e com perfis profissionais variados, descritos na Tabela 1 . A experiência em gestão foi um dos critérios adotados para a escolha de participantes oriundos de programas de MBA devido à possibilidade de maior riqueza de dados para interpretação que pode ser obtida entre gestores mais experientes, perfil dos integrantes desse tipo de curso.

Tabela 1

Perfil Profissional dos Entrevistados

\begin{tabular}{|c|c|c|c|c|c|}
\hline Sujeito & Idade & Cargo atual & Atuação da empresa & Formação & Pós-Graduação \\
\hline Helena & 30 & Controller de Segmento & $\begin{array}{l}\text { Indústria de } \\
\text { tecnologia }\end{array}$ & Economia & Finanças Intl. Londres \\
\hline Vasco & 35 & Gerente de Planej. e MKT & Comunicação & Economia & MBA - Belo Horizonte \\
\hline Guilherme & 37 & Diretor de operações & Comunicação & Administração & MBA Califórnia - USA \\
\hline João & 37 & Gerente de Planej. e MKT & Instituição Financeira & Comunicação & MBA - Porto Alegre \\
\hline Ana Niza & 41 & Gerente de RH & $\begin{array}{l}\text { Indústria de } \\
\text { mecanização agrícola }\end{array}$ & Administração & MBA - Porto Alegre \\
\hline Sofia & 45 & Sócia-proprietária & $\begin{array}{l}\text { Assessoria de } \\
\text { mercado química e } \\
\text { petroquímica }\end{array}$ & $\begin{array}{l}\text { Engenharia } \\
\text { química }\end{array}$ & MBA - Porto Alegre \\
\hline Augusto & 55 & Presidente & Instituição Financeira & $\begin{array}{l}\text { Administração } \\
\text { Contabilidade }\end{array}$ & MBA - Porto Alegre \\
\hline
\end{tabular}


Inicialmente os participantes foram selecionados a partir de uma relação de contatos de ex-alunos, egressos de um curso de MBA Executivo, cedida pela Universidade promotora para a realização do presente estudo. A partir do primeiro contato com os entrevistados, foram solicitadas indicações de excolegas e de outros profissionais com o perfil desejado para integrarem o estudo de modo voluntário, conforme indicam Sheftel e Zembrzycki (2010). Desta forma, foram recrutados dos novos participantes, portanto, utilizando-se a técnica snowball (Biernacki \& Waldorf, 1981), ou bola de neve, na qual os participantes iniciais de um estudo indicam novos participantes, sucessivamente, buscando-se obter a composição de um grupo heterogêneo de entrevistados.

A ausência de uma relação direta entre pesquisadores e entrevistados pode ter dificultado, inicialmente, o compartilhamento de pensamentos e sentimentos mais profundos, como sugerem Maclean, Harvey e Chia (2012). Por outro lado, considera-se que a ausência de vínculos prévios contribuiu para reduzir a interferência na objetividade das análises que um vínculo emocional pode gerar (Smith, 2012) e a tendência à construção de trajetórias heroicas por parte dos entrevistados, estratégia frequentemente utilizada para legitimarem-se no ambiente organizacional (Maclean, Harvey, \& Chia, 2012).

Czarniawska (2004) ressalta a simetria na assimetria de poder entrevistador-entrevistado, quando os narradores são os especialistas em suas próprias vidas e em sua profissão. A exposição de pensamentos por parte dos profissionais, especialmente dos que ocupam altas posições hierárquicas, tem consequências práticas e políticas, o que os leva, frequentemente, a pensar de modo solitário. Nesse sentido, após a dificuldade inicial em obter a concordância para a participação na pesquisa, sobretudo pela falta de tempo desses profissionais, percebeu um interesse genuíno dos gestores em compartilhar suas trajetórias, experiências, conquistas e dificuldades com a pesquisadora.

As entrevistas foram agendadas previamente, sendo realizadas em locais escolhidos pelos participantes (sala de trabalho, sala reservada na empresa, café, residência), buscando-se um ambiente tranquilo, para que o(a) entrevistado(a) pudesse falar livremente, como sugerem Maclean et al. (2012). Nesse contato inicial, o objetivo da pesquisa foi informado e solicitou-se a concordância com a gravação das entrevistas, garantindo-se o anonimato dos participantes, como forma de estabelecer, desde este primeiro momento, uma relação de confiança, essencial nesse tipo de estudo (Sheftel \& Zembrzycki, 2010).

$\mathrm{Na}$ primeira entrevista, solicitou-se aos executivos que discorressem livremente sobre suas trajetórias de vida, destacando experiências que impactaram significativamente em suas carreiras. Neste momento, não foram feitas intervenções, exceto respostas às dúvidas dos entrevistados, uma vez que, nesse tipo de entrevista, o(a) pesquisador(a) deve assumir a posição de "seguir os atores" (DeloryMomberger, 2012, p. 528), dando liberdade aos narradores para contarem suas histórias e identificarem seus aspectos significativos (Smith, 2012).

Seguindo Denzin (1989), adotou-se a estratégia interpretativa para a análise das histórias de vida. Conforme proposto por Demartini (1988), a cada encontro com os entrevistados, foram registradas observações consideradas importantes em um diário de campo, tais como comentários dos gestores após o término da gravação, percepção de sentimentos, questões a serem aprofundadas e outros elementos que poderiam ser explorados em nova(s) entrevista(s). Os relatos foram, imediata e fielmente, transcritos e analisados, gerando novas perguntas para a(s) entrevista(s) seguinte(s) que auxiliassem a compreensão de aspectos propostos pelo estudo, formuladas em consonância com os objetivos da pesquisa, tal como realizado por Xing e Sims (2012). Os temas que surgiram nas narrativas ampliaram as discussões e as análises, tal como observou Smith (2012). Ao final da última entrevista, solicitou-se a cada gestor que sugerisse um nome fictício para ser usado na pesquisa (Ana Niza, Augusto, Guilherme, Helena, João, Sofia, Vasco). A pesquisa empreendida envolveu entre duas e três entrevistas (de uma hora a uma hora e meia de duração) com cada gestor, perfazendo um total de dezessete encontros, que resultaram em trezentas e dez laudas de transcrições. 
Para a elaboração dos resultados, seguiu-se a análise de narrativas temáticas, onde as narrativas transcritas são organizadas por temas, criados indutivamente a partir de um conjunto de histórias (Riessman, 2005).

Após a realização de leituras atentas de cada história de vida, buscando experiências e significados relevantes para cada entrevistado, foram destacados trechos das narrativas, constituindo-se categorias amplas. A análise dos diversos trechos selecionados possibilitou a identificação de subcategorias, envolvendo padrões de experiências e significados semelhantes, testadas e reformuladas continuamente, procedimento realizado igualmente por Xing e Sims (2012). A fim de analisar temas comuns e, simultaneamente, manter peculiaridades individuais, a síntese de cada história foi escrita e excertos de seus relatos ilustrativos foram incluídos na análise, assim como em Smith (2012). Este procedimento foi adotado na análise dos relatos de história de vida dos três primeiros participantes, propiciando a identificação de categorias relevantes para a compreensão da questão de pesquisa proposta pelo estudo. A partir do quarto entrevistado, os relatos das histórias de vida foram igualmente sintetizados, lidos e relidos, analisados e subcategorizados, conforme os anteriores, sendo o conteúdo das narrativas sistematizado em mapas inspirados pelo modelo de Spink e Lima (2000), compreendendo as informações mais importantes para o processo de análise.

Os registros dos trechos expressivos foram destacados no texto que compreendia a história de vida completa de cada gestor, a fim de facilitar a localização e a transposição posterior de relatos que pudessem exemplificar as análises conjuntas do tema pesquisado. Concluídas as análises individuais dos três primeiros gestores entrevistados e as análises e os mapas dos demais, o conjunto de informações foi analisado, envolvendo a identificação de semelhanças e diferenças, a redefinição de categorias, e a interpretação com base em referenciais teóricos previamente estabelecidos e decorrentes dos resultados, em conformidade com Riessman (2005).

Assim, a análise pode ser marcada por dois momentos, o primeiro, no qual se buscou compreender a trajetória individual de cada gestor, e o segundo, quando se procurou levantar aspectos que fossem similares no conjunto das trajetórias. Desta forma, chegou-se às categorias que serão apresentadas na seção seguinte.

Entre as limitações associadas à aplicação do método, destaca-se o tempo necessário tanto para a realização da pesquisa, que envolve uma série de entrevistas (Atkinson, 2002), como para a transcrição dos relatos e a análise de cada um deles (Riessman, 2005), restringindo o número de participantes no estudo e, possivelmente, a identificação de outros elementos passíveis de análise. Ainda associada ao tempo, está também a dificuldade em obter a concordância dos profissionais em participarem da pesquisa, devido ao acúmulo de compromissos que os executivos possuem nas organizações. Assim, a concessão de, pelo menos, duas entrevistas de uma hora de duração, foram barreiras iniciais no presente estudo. Outras limitações, associadas ao agrupamento de narrativas em categorias temáticas semelhantes, são a possibilidade de que nem todos os entrevistados confiram o mesmo sentido aos temas expressos e o risco de que respostas desviantes do grupo possam ser desconsideradas no estudo (Riessman, 2005).

\section{Apresentação dos Resultados}

Esta seção apresenta, em caráter ilustrativo, resultados encontrados a partir das entrevistas de história de vida realizadas com os gestores brasileiros. Destaca-se que, para a organização dos dados na história de vida, é importante construir a trajetória dos entrevistados sintetizando suas histórias e mantendo a riqueza dos detalhes. Esta etapa não será apresentada neste trabalho, pois a descrição densa requer um espaço maior do que o de um artigo para ser realizada. A seguir, apresenta-se uma síntese dos resultados da pesquisa, em duas seções: (a) influências do contexto nas carreiras; (b) momentos da vida e escolhas profissionais. 


\section{Influências do contexto nas carreiras}

Nesta seção, exploram-se aspectos sociais, econômicos e políticos ligados à conjuntura brasileira durante o desenvolvimento da carreira pelos entrevistados. Nas entrevistas dos gestores, emergiram como categorias relevantes as mudanças no cenário econômico e organizacional nos anos 1990, a maior concorrência e a necessidade de aprofundar conhecimentos, a demanda por mobilidade e as diferenças de gênero.

\section{Mudanças no contexto econômico e organizacional brasileiro}

No início da década de 1990, as mudanças no contexto econômico brasileiro, como a abertura do mercado brasileiro às empresas estrangeiras e o aumento da competitividade, marcaram algumas trajetórias profissionais. Com a recessão no mercado interno e a ameaça dos produtos estrangeiros, nos anos 1990, o conceito de qualidade tornou-se palavra de ordem na indústria e os preços passaram a ser ditados pelo mercado internacional, tornando a gestão de custos um determinante na lucratividade das empresas. Apesar de realizadas em tempos e trajetórias diferentes, o padrão de mudanças organizacionais adotado pelas empresas mais avançadas no Brasil envolveu, basicamente (Fleury \& Fleury, 2006): (a) um reposicionamento no mercado, através da reestruturação interna, terceirização e racionalização das atividades produtivas; (b) a introdução de novos métodos de gestão da produção, tais como Total Quality Control e Just in Time; (c) a redefinição do processo de trabalho; e (d) a reorganização da empresa como um todo.

Exemplificando a influência dessas mudanças nas carreiras dos entrevistados, as novas tecnologias incorporadas por um concorrente trouxeram grandes dificuldades para a empresa onde João trabalhava, motivando-o a procurar um novo emprego no segmento de telefonia móvel, em fase inicial no Brasil. Helena trabalhou na mesma empresa, naquele momento, uma vez que oferecia uma boa remuneração e perspectivas de desenvolvimento de carreira. Já Sofia sentiu-se frustrada e insegura ao ver seus colegas sendo demitidos a partir da privatização e da implementação de um programa de reengenharia na petroquímica onde trabalhava, um dos fatores que a motivou a montar o seu próprio negócio. Essas modificações econômicas e tecnológicas reconfiguraram o mercado de trabalho e alteraram significativamente o curso das carreiras e profissões durante o período, representando limites às carreiras pessoais, que também podem ser visualizados na pesquisa realizada por Ituma e Simpson (2009) sobre os trabalhadores de tecnologia da informação na Nigéria.

\section{Globalização e novas demandas educacionais}

A maioria dos gestores buscou um MBA depois de adquirir experiência de trabalho e crescimento profissional. Por serem cursos considerados caros, sua realização foi possível por meio de financiamento de suas empresas. Entre as motivações mais comuns para fazê-lo, estão o desejo de aumentar a qualificação, o reconhecimento institucionalizado no mundo dos negócios que esses cursos fornecem e as perspectivas de crescimento financeiro e profissional. Do ponto de vista econômico de pesquisa da carreira, o valor do capital humano refletido em um MBA pode ser visto aqui (Khapova \& Arthur, 2011).

A importância conferida à realização de cursos no exterior foi expressa nos relatos das vivências de Guilherme e Helena e no sonho em realizar um MBA no exterior declarado por Vasco. A fala de Vasco ilustra a posição dos entrevistados:

\footnotetext{
"a gente sabe que tem MBAs de um nível muito maior fora, né? Falar, só pra citar os que eu me lembro, assim, Harvard, MIT, sei lá, Kellog, UCLA, INSEAD, na Europa, London Business School, na Inglaterra, INSEAD na França e tal. Então, são cursos melhores, assim, do ponto de vista não só de reconhecimento, mas, de fato, cursos mais intensivos.... além, também, da questão, assim, de um networking, que eu fiz no MBA ..., mas é um networking diferente do networking que eu faria, por exemplo, numa Harvard ... E também a questão da língua, eu acho que isso também é uma coisa importante, a questão de tu estudares, assim, estudar e morar durante dois anos falando inglês, praticamente ... até por conta disso tudo, o reconhecimento, né? A gente sabe que o pessoal que faz MBA nessas top 10 no mundo são pessoas que são demandadas, são procuradas para empregos importantes, empresas importantes."
} 
Esta fala evidencia uma característica do sistema de ensino brasileiro: a valorização da formação no exterior. O ensino de Administração no Brasil caracterizou-se pela importação de tecnologia desenvolvida especialmente nos Estados Unidos (Nicolini, 2003), motivo pelo qual os cursos de MBA nesse país e em outros centros econômicos são ainda muito valorizados. Para os que não conseguiram realizar cursos no exterior, como Vasco, o MBA foi cursado numa instituição de renome no Brasil, uma forma intermediária de manter a qualificação requerida.

A importância de aprender Inglês para crescer profissionalmente em grandes empresas, mesmo as que operam apenas no mercado doméstico, também foi destacada. Apesar de Sofia não falar Inglês, ela via o desafio colocado pelo processo de internacionalização que sua empresa estava passando, exigindo novas habilidades. Já Helena, por ter vivido na Inglaterra por causa do trabalho dos seus pais, adquiriu a fluência em Inglês, elemento que a diferenciava profissionalmente e que favoreceu a sua carreira. A disposição para aprender e viajar em busca de aprendizado se mostrou um elemento importante e, em alguns relatos, essencial para o desenvolvimento da carreira. No entanto, o domínio de um idioma estrangeiro no Brasil não é possível sem investimento financeiro, pois a formação oferecida pelo sistema público de ensino não possibilita desenvolver fluência em qualquer língua estrangeira. No caso dos MBAs, verifica-se uma situação ainda mais excludente, pois o investimento necessário para sua realização limita significativamente a parcela da população que consegue acesso a esses cursos. Esses aspectos evidenciam a influência do contexto nos limites de carreira, tal como observou Ituma e Simpson (2009). Além disso, tal como Khapova e Arthur (2011) apontam, o conhecimento de idiomas, ou a facilidade de se comunicar em um mercado global surge como elemento de destaque nas novas configurações de carreira. Desta forma, a emergência de requisitos ligados a uma formação global pode vir a se constituir uma barreira para aqueles que não têm recursos suficientes para realizar investimentos voltados para desenvolvê-la.

\section{Mobilidade}

A fim de mover-se profissionalmente, Vasco deixou um cargo de coordenador de planejamento em Porto Alegre para ser gerente de finanças em outro estado, um desafio que lhe deu a oportunidade de ver todo o negócio da organização para a qual trabalhava. Ao retornar para Porto Alegre, ele novamente trocou de departamento, indo para a área de marketing. João nunca morou em outra cidade, embora tenha realizado uma série de treinamentos, em São Paulo, na sede de uma multinacional em que trabalhou, e tenha viajado pelo Brasil. Ele demonstrou alguns sentimentos ambíguos com relação a possibilidades profissionais em mercados mais desenvolvidos, como em São Paulo ou no exterior, mas se questionou se o que o impede de buscar novos horizontes é o apego à família ou o receio de sair. Os seus sonhos parecem também contraditórios:

\footnotetext{
"não tenho nenhum sonho de morar, assim, em outros países, embora os sonhos existam, mas talvez os convites profissionais possam me levar a isso, quem sabe? Mas não é algo que eu tenha, assim, ah, eu quero agora me mudar para Miami. Não é que eu queira ter uma super casa... Claro que a gente quer, eu quero melhorar, quero ter aquisições materiais, quem sabe mudar para uma casa, eu moro em um apartamento hoje. Mas é, eu acho que não é muito mais que isso não. Quero viver bem, com... Porque se sobra muito de um lado, falta do outro. Então não adianta, né? Ter uma vida, entre aspas, assim, ecológica."
}

Esta ambiguidade de sentimentos pode ser decorrente de sua percepção de que viver em São Paulo ou no exterior poderia trazer a ele uma série de novos aprendizados e oportunidades profissionais, mas envolveria também riscos e incertezas, gerando receios.

Ana Niza exprimiu que assumir um desafio profissional em São Paulo, vivenciando uma cultura diferente, com uma forma de se posicionar e de trabalhar bem diversa daquela dos gaúchos, foi um aprendizado importante para ela. Além disso, destacou o crescimento pessoal que foi aprender a viver sozinha, longe de suas raízes. Para Sofia, suas viagens à região sudeste hoje são vitais para seu negócio, pois lá se encontram praticamente todos os seus clientes. Quando fundou seu negócio, segundo ela, não era assim. Isto se deu em função da maior concorrência global, que acarretou reestruturações organizacionais e fusões entre as empresas do setor químico e petroquímico em resposta ao aumento de competitividade, bem como na concentração destas empresas neste polo econômico. Conforme Sofia, 
analisando somente os objetivos do negócio, a empresa deveria estar em São Paulo, mas ela e os sócios decidiram permanecer no Rio Grande do Sul por uma opção pessoal.

Augusto foi enviado para a França durante um ano para trabalhar na sede da corporação em que atuava, como administrador, experiência de mudança cultural que expandiu seus horizontes profissionais. Para o entrevistado, os executivos precisam estar prontos e dispostos a viajar e a se mover como resultado da globalização e do dinamismo econômico. O desafio de morar em outro país envolveu muita negociação com sua família, pois ele teria que permanecer três semanas na Europa e uma no Brasil, onde sua família ficaria. Essa experiência foi bastante difícil e desgastante, quando teve que aprender a conviver com o afastamento familiar e a lidar com as dificuldades decorrentes desse distanciamento também para a família:

"a ausência do meio familiar gera realmente um desconforto muito grande e sobra, entre aspas, para a mãe de família.... Mas é preciso que haja um entendimento muito bom na família, com esposa, filhos, inclusive, para que não se comprometa esse plano... do executivo. Pode ser até dela, seria a recíproca também. É preciso que haja essa discussão, esse acordo, esse entendimento de que... é uma necessidade.”

$\mathrm{Na}$ fala dos entrevistados a mobilidade surge como um fator capaz de proporcionar diferencial na trajetória profissional, uma vez que permite acesso aos grandes centros, ampliar aprendizado e rede de contatos. Essa mobilidade, no entanto, impõe sérios limites na vida pessoal, constituindo-se uma fronteira para aqueles profissionais que não têm tal mobilidade, como apontam Chudzikowski e Mayrhofer (2011).

\section{Discriminação de gênero}

Para as mulheres, questões de gênero podem se impor como limites nas suas trajetórias profissionais. Sofia expressou a limitação percebida por ela, em função de ser mulher, para desenvolver a sua network - aspecto extremamente valorizado entre os gestores - quando destacou que teve que aprender a se proteger em algumas situações.

"Para a mulher é mais difícil, porque até que ponto tu podes se aproximar de uma pessoa e ter uma relação um pouco mais pessoal com ela, que normalmente são homens, entendeu? Esse que é o problema, esqueci de te falar desse detalhe, então a maioria são homens. Então, por exemplo, eu viajo.... Eles [colegas homens] vão e já marcam o café da manhã com um, o almoço com outro, janta com outro.... Eu me limito a fazer reuniões no horário administrativo, ou no máximo um café da manhã, ou um almoço, mas jamais uma janta. Porque já tive experiências muito ruins nesse sentido, entendeu? Da pessoa achar que é outra coisa, ou então tu vai lá e tu convida o cara para jantar para conversar um pouco sobre o trabalho e ele vai ter mil dificuldades para explicar para a mulher dele que ele vai estar saindo com a [Sofia] para jantar. Então isso para mim é bem, assim, uma coisa que eu me surpreendi, eu demorei para cair a ficha. Mas eu me surpreendi, me surpreendo até hoje com as dificuldades que a gente tem nesse sentido, né? Muita dificuldade."

Assim, as executivas aprendem a sobreviver em um mundo que, embora lentamente se transforme, ainda é marcado pela valorização do masculino.

Helena disse estar muito realizada em termos pessoais com o seu casamento e com a sua gravidez, achando muito importante sempre conseguir conciliar isso. Preocupava-se em conseguir equilibrar, com o nascimento da filha, um tempo de qualidade com a família e sua ascensão na carreira, desafio que considerava bem grande.

A visão dos homens sobre a importância do trabalho feminino também vem mudando. Vasco compartilhou com a esposa a decisão de trabalhar e morar sozinho em Santa Catarina por um tempo, respeitando a importância da carreira dela. A recusa de uma promoção de trabalho com o objetivo de retornar a Porto Alegre esteve também vinculada à esposa, pois ela é médica, carreira que, conforme Vasco, seria prejudicada caso tivesse que ser reiniciada. 
Percebe-se que também os homens estão buscando se adequar às mudanças decorrentes da maior participação das mulheres no mercado de trabalho. Como se observa, as questões ligadas a gênero podem surgir como limites dentro de uma determinada carreira ou profissão, embora as transformações no mercado de trabalho no contexto brasileiro venham contribuindo para amenizar essas diferenças.

\section{Momentos da vida e escolhas profissionais}

Nesta seção, o foco recai sobre aspectos individuais das trajetórias dos entrevistados, destacando elementos como valores e família, escolha do curso, ingresso no mercado de trabalho e nascimento dos filhos.

\section{Valores e família}

Os interesses e as decisões a respeito da futura profissão, bem como os fatores que limitam as possibilidades de escolhas profissionais podem surgir ainda na infância, nas interações com a família e com a comunidade vizinha. A importância da família e dos valores, no caso dos entrevistados, destacouse especialmente nos seus traços culturais, associados às descendências italianas e germânicas, em particular, frequentemente mencionadas nas suas falas, uma identificação cultural frequente no Sul do Brasil, onde inúmeras famílias são originárias de imigrantes europeus. Guilherme destaca entre os valores que adota até hoje a integridade e a valorização das pessoas no aspecto moral, pelo caráter e não apenas por questões materiais. Seu relato demonstra ainda a valorização de desafios e conquistas, espelhados no modelo do pai, que sempre teve negócios:

"Ele [pai] não chegou a concluir a faculdade de administração, só teve uma formação da vida, assim, muito na prática, que eu acho que é superimportante. Quando a gente não conhece, ver as pessoas atuando [referindo-se ao pai], acho que é uma das formas de aprendizado muito grande - até, uma das principais formas de aprendizado no trabalho é ver os outros atuando. Então, a questão de negociação, a questão de valorizar o que se tem, de valorizar as conquistas, valorizar os desafios. A questão de conquistar e de se trabalhar esse conquistar, acho que principalmente esses pontos."

Helena aponta o impacto positivo que a orientação recebida dos pais de levar a sério estudos e trabalho trouxe posteriormente em suas experiências laborais, valorizando-a profissionalmente. João demonstrou ter sido bastante significativo o aprendizado de cumprir com o que foi prometido a outras pessoas, muito valorizado por sua família, aspecto que também o favoreceu em sua atuação profissional:

"Muitos dos clientes que eu atendia na empresa X eu consegui fechar negócios na Y e aí a questão dos relacionamentos numa área comercial é muito importante ... Confiança, acho que isso é o principal ingrediente dessa atividade, é a confiança, a credibilidade ... Porque a gente conhece eles [sic], já nasceu aquele respeito, se estabelece essa confiança."

Sofia percebeu, em sua formação alguns valores que ela denominou "uma coisa bastante germânica", tais como o cumprimento de horários. João associou a sua aprendizagem de princípios e valores, tais como disciplina e religião, aos modelos de seu pai e avô, enfatizando as origens de seus avós, imigrantes italianos. Augusto relacionou à sua ascendência o seu espírito de mudança, que ele acredita que contribuiu para o seu crescimento profissional, oriundo de seus avós, que emigraram da Itália. Essas influências de identificações étnicas são exemplos da visão da carreira a partir da perspectiva da psicologia social (Khapova \& Arthur, 2011).

\section{O ingresso no ensino superior como marco da definição profissional}

A conclusão do ensino médio e a chegada aos 18 anos de idade no Brasil representam importante momento de passagem para a vida adulta, incluindo aspectos legais, que sinalizam um momento de transição. A entrada no ensino superior, social e culturalmente, representa maior autonomia e liberdade, mas também assumir responsabilidades e a necessidade de busca de caminhos profissionais que possam levar à independência financeira. A definição profissional é marcada pelo rito de aprovação no vestibular e pela posterior inscrição em uma faculdade ou universidade. Essa trajetória, comum aos entrevistados, 
segue um padrão determinado pelas expectativas geradas no âmbito social desse grupo, referindo-se a uma perspectiva de análise tradicionalmente adotada pela sociologia.

Em função dos poucos recursos de sua família, a reprovação no vestibular em uma universidade federal gratuita conduziu Augusto à mudança de rumo e à adaptação às possibilidades existentes:

“eu havia tentado uma faculdade de agronomia, já que eu me identificava um pouco com a produção agrícola e tal, mas eu não fui feliz no vestibular e não consegui passar, aqui na UFRGS. E também não tinha condições de fazer cursinho. Então decidi mudar de rumo. Foi aí que ... pois bem, vamos fazer o que é possível. E o que era possível era uma faculdade de economia lá da região, em Bento Gonçalves. Fiz um ano e meio, acho que ... três semestres e aí é que eu decidi ir a São Paulo buscar oportunidades.... Então, eu decidi continuar os meus estudos em São Paulo, porém mudando de Economia para Administração, até por comodidade, porque eu tinha que fazer recuperações e adaptações, lá em São Paulo.”

A necessidade de sustentar-se na capital, uma vez que a mãe morava no interior, foi decisiva na opção de Ana Niza por cursar Administração. Conforme ela expressou,

"na verdade, eu queria fazer Psicologia.... Só que, como eu tinha que pagar a minha faculdade, ou não pagar a faculdade, mas ter que trabalhar pra me virar - a faculdade de Psicologia da UFRGS, primeiro, era, na época que eu fiz a inscrição, uma vaga pra cada trinta e cinco pessoas. Eu não sei como é que está agora, mas, na época, era bem concorrida. E tinha um senão que eram as aulas serem de dia. Ou seja, te impossibilita um pouco de trabalhar, se tu precisas. Aí eu pensei assim: o que, de repente, eu consigo fazer ... que não me distancie tanto da Psicologia, né, e que de repente eu possa usar - mas eu nem imaginava que era, que existia Administração de Recursos Humanos, assim. Então, eu acabei fazendo a escolha, meio que ... o que dava pra fazer. E que eu conseguia conciliar e fazer a faculdade, sem ter que pagar a faculdade, que eu não ia conseguir. Então eu acabei optando pela Administração."

Assim, a perspectiva sociológica permite observar que não ser aprovado no vestibular para uma universidade pública gratuita, a necessidade de se deslocar para os grandes centros urbanos e as limitações de recursos financeiros da família influenciaram as trajetórias e a formação educacional escolhida por alguns dos entrevistados. A perspectiva psicológica também possibilita analisar, nessas situações, influências nas carreiras da busca por satisfazer necessidades pessoais e a capacidade adaptativa dos indivíduos em face de suas experiências vividas (Khapova \& Arthur, 2011).

\section{Primeiras experiências profissionais}

As primeiras experiências profissionais levaram à definição dos caminhos tomados por muitos dos entrevistados. Esta orientação foi muitas vezes definida por acaso, motivada pela busca financeira e por oportunidades resultantes das suas primeiras experiências profissionais. Na fala da maior parte dos entrevistados, nota-se que os direcionamentos de carreira não ocorreram através de escolhas conscientes, mas foram decorrências de suas primeiras experiências profissionais, evidenciando que, no Brasil, o ingresso no mercado de trabalho é um momento marcante para a definição do futuro profissional, como afirmam Rocha-de-Oliveira e Piccinini (2012).

Nesta fase, os profissionais ainda estão em busca de um caminho a seguir, como expressa o relato de Guilherme, comentando sobre a experiência em seu primeiro estágio:

"Foi uma experiência importante para ter uma realidade, assim, mas, olhando para trás, só como experiência. Eu era bem infeliz naquilo... E eu tinha, continuava com as inseguranças de futuro, de realização profissional, de carreira, sem saber, assim, muito preocupado com a quantidade de pessoas, fazendo a mesma coisa que eu na faculdade, e de que forma eu me diferenciaria e, ao mesmo tempo, poderia ter sucesso por me diferenciar e seria também realizado, né, pessoal e profissionalmente."

No primeiro estágio realizado por Ana Niza, a pessoa que a admitiu foi demitida e a própria Ana assumiu seu lugar, uma posição na área de Recursos Humanos em uma indústria têxtil, onde teve que aprender a realizar uma série de atividades que desconhecia. 
"eu me lembro de que o primeiro processo de seleção que eu fiz foi pra uma vaga de comprador. Que não é uma vaga fácil ... E a primeira entrevista ele fez, ele conduziu, né? E eu junto ouvindo o processo todo e tal. Aí, na segunda, ele já me disse assim: bom, agora na segunda tu vai fazer e eu vou ouvir. Eu disse: mas como? Não, agora tu vai fazer e eu vou ouvir. Então, eu fiz a segunda. Claro, errei um monte de coisas, gaguejei e tal, blá, blá, blá. E, na terceira, também [risos] eu fiz, daí fui um pouquinho melhor.”

Augusto, em São Paulo, teve a oportunidade de administrar um negócio relacionado a vinhos, um produto que ele já conhecia devido a um curso de enologia que fez na região vinícola onde nasceu. $\mathrm{O}$ negócio prosperou, e ele continuou a estudar, a fim de avançar profissionalmente em empresas de grande porte - um símbolo de status, para ele - em parte, motivado pelo desafio de mostrar aos seus colegas de faculdade que trabalhavam para essas empresas que ele também teria sucesso.

Guilherme buscou programas de trainee em grandes empresas, acreditando que estes lhe proporcionariam possibilidades de crescimento na carreira. Escolhendo trabalhar no departamento financeiro de uma delas, ele decidiu desenvolver-se neste campo, do qual não sabia nada.

Nestes casos, o entrelaçamento das perspectivas de agência e estrutura (Smith, 2012) podem ser vistos, remetendo para o cruzamento das perspectivas psicológica e social, uma vez que envolve indivíduos aparentemente únicos, mas que são profundamente influenciados pela interação com o meio ambiente (Delory-Momberger, 2012; Denzin, 1989).

\section{A constituição da própria família}

A maioria dos entrevistados é casada e tem filhos, com exceção de Ana Niza. Helena, quando entrevistada, estava grávida de sete meses. Especialmente para as gestoras, constituir uma família foi destacado como um período marcante que levou a uma mudança de significados psicológicos, descentrando o foco de si próprias. Sofia e Helena escolheram engravidar na faixa etária de 28-30, depois de atingirem vários objetivos de carreira, devido à dificuldade em conciliar a vida profissional e a pessoal.

As preocupações de Helena estavam centradas na maternidade, na saúde de sua filha, no período de licença maternidade e no retorno ao trabalho, após o nascimento da filha. Ela desejava poder estar próxima da filha, educá-la, mas, ao mesmo tempo, queria manter sua carreira em ascensão, conciliando o tempo para a família e para a carreira, o que considerou um grande desafio. Sabia que, pela localização do seu emprego, na época - que desejava manter - não poderia almoçar em casa e questionava-se como conseguiria estar presente e acompanhar a filha só com algumas horas à noite e pouquíssimas pela manhã. Este dilema é comum entre os entrevistados com filhos, fator que lhes gera alguns sentimentos de culpa e preocupações.

Sofia teve dificuldade para engravidar, em função de um problema do marido. Mesmo assim, ela se sentia culpada por adiar a gravidez, já que ela teve que recorrer a um processo de fertilização, outra das razões pela qual ela deixou o trabalho que tinha realizado durante 7 anos na indústria, a fim de iniciar seu próprio negócio, uma vez que o tratamento de fertilização exigia um nível de disponibilidade que ela não tinha em seu trabalho. Neste caso, é possível observar a formação de limites de carreira internos (Chudzikowski \& Mayrhofer, 2011), a partir da culpa sentida por Sofia e da escolha que a levou a um redirecionamento de sua carreira.

Guilherme também expressou que trabalhava muito e que se sentia culpado quando não conseguia dar atenção para o filho. Ele apontou a descoberta de ser pai e a mudança de papel e do foco sobre si, que agora recai mais sobre a responsabilidade que tem para com o filho: "eu sou pai há três anos e meio, isso tem sido uma baita descoberta, assim, eu sinto que hoje eu tenho um papel diferente. Acho que até antes de eu ser pai era sempre assim: o que eu vou ser, o que eu vou construir".

Em seus relatos, Sofia estrutura grande parte da linha de tempo em suas narrativas em função dos filhos, tal como exemplifica a sua fala, em que narrou sobre a volta aos estudos, quando os filhos completaram cinco anos: 


\begin{abstract}
"Quando eles [filhos] fizeram cinco anos, eu resolvi então voltar a estudar, que também era uma coisa que eu queria muito, que eu achava que era importante para minha profissão, que era ter um título, não só pelo título de mestre, mas ter o título, ter um upgrade no meu currículo e poder colocar dentro da empresa uma coisa mais acadêmica, de metodologia... dar uma reciclada mesmo.... Acho até assim que foi perfeito o período que eu escolhi para fazer a pós porque os primeiros cinco anos, sempre é difícil, né? Eles são pequeninhos, aí fica doente, tem muito aquele envolvimento emocional, até. Eu tinha estrutura, tinha babá, tudo, mas tu estás sempre muito preocupada e eu acho que eu não ia ter muita cabeça para estar fazendo uma outra atividade."
\end{abstract}

Com a chegada dos filhos, Sofia expressou ter dosado um pouco melhor seu padrão de exigência para com outras coisas, pois o tempo começou a ficar escasso.

Além de demandar novas organizações de tempo, João referiu-se a outra mudança que percebeu ao tornar-se pai, no sentido de "olhar um pouco menos para o próprio umbigo". Augusto relatou uma série de questionamentos, a partir do nascimento da primeira filha, sobre a poluição e a criminalidade em São Paulo, que não havia se feito até então:

"um momento marcante para mim, quando nasceu a minha primeira filha, em mil novecentos e oitenta ... São Paulo estava muito... em ebulição, os problemas sociais estavam se iniciando, problemas mais sérios, criminalidade e principalmente problemas de poluição. E me marcou muito aquela história de que, caramba, como é que nós vamos viver nesse ambiente? Pra quem nasceu no interior, né, como é que nós vamos viver nesse ambiente, como é que nós vamos criar filhos nesse ambiente tão poluído, tão... E surgiu a oportunidade da mudança, e eu nem vou pensar duas vezes, eu vou embora."

Para os homens, a responsabilidade por prover sustento para a família faz com que diminua a sua disposição para assumir riscos profissionais. Há também uma maior demanda pelos filhos de atenção, carinho e educação, o que exige disponibilidade de tempo, escasso para a maioria dos entrevistados, gerando sentimentos de culpa e esforços para conciliar essas esferas.

$\mathrm{Na}$ fase de constituição da família, nota-se a formação de um novo momento de carreira no qual o foco sobre o trabalho é refletido e revisto pelos entrevistados. Todos relataram que conciliar a incorporação de um novo papel (paternidade, maternidade) com suas expectativas profissionais se mostrou um desafio e serviu como base para definições sobre os seus ritmos de trabalho. Essa transformação é mais significativa para as mulheres que, em alguns casos, redefiniram totalmente sua carreira para poder conciliá-la com a maternidade. Aqui, a opção pela formação de uma família pode representar uma barreira tanto interna, em função dos valores e crenças dos indivíduos, quanto externa, por meio das expectativas dos grupos sociais de que participam, quanto à forma compreendida como correta de se dedicar à criação e à educação dos filhos.

\title{
Considerações Finais
}

Este artigo apresentou algumas possibilidades e limitações que o uso da abordagem de história de vida pode oferecer para a pesquisa interdisciplinar sobre carreiras. Alerta-se, assim, a necessidade de se refletir sobre abordagens de pesquisa que possibilitem avanços nesse campo teórico, integrando conhecimentos de distintas disciplinas. Baseado em entrevistas de história de vida com gestores brasileiros, diversos aspectos envolvidos no desenvolvimento de carreiras foram ilustrados a partir de perspectivas de análise provenientes da Psicologia (escolhas profissionais e capacidade de redirecionamento), da Sociologia (influência das expectativas sociais, exigências técnicas e educacionais), da Psicologia Social (influência de origens familiares) e da Economia (valor do capital humano), de modo interligado e complementar.

Deve ser ressaltado que os dois grandes eixos (influências do contexto e momentos de vida) tiveram um caráter predominantemente didático para facilitar a apresentação da análise dos dados, uma vez que os elementos contextuais influem nas trajetórias individuais, e as ações individuais representam 
diferentes formas de reconhecer e assimilar as alterações no contexto. Desta forma, contexto e trajetória profissional apresentam várias intersecções, que são brevemente sintetizadas na Tabela 2.

Tabela 2

Influências do Contexto e dos Momentos de Vida nas Trajetórias Profissionais

\begin{tabular}{lll}
\hline Perspectivas de análise & Influências do Contexto & Influências dos momentos de vida \\
\hline Psicológica & Vivências diferentes em função de gênero & $\begin{array}{l}\text { Razões da escolha do curso } \\
\text { Redirecionamento da carreira }\end{array}$ \\
Sociológica & Mudança nas organizações & Busca de cursos para aprimoramento \\
& Internacionalização dos mercados & \\
Exigência de maiores qualificações & \\
& Exigência de mobilidade & \\
Econômica & Mudanças no cenário econômico nacional & $\begin{array}{l}\text { Suporte econômico para a família } \\
\text { ascendente ou descendente }\end{array}$ \\
\hline
\end{tabular}

$\mathrm{Na}$ organização da tabela, destaca-se que alguns elementos contextuais interferem mais significativamente na trajetória de determinados sujeitos. Um exemplo é a discriminação de gênero que acaba contribuindo para a formação de trajetórias distintas para homens e mulheres numa mesma profissão. Da mesma forma, os valores familiares, destacados em várias entrevistas, muitas vezes estão ligados a aspectos da cultura regional, como é o exemplo dos entrevistados oriundos de regiões de colonização alemã e italiana. Também as mudanças no contexto dos anos 1990 levaram a diferentes implicações para as trajetórias individuais, dependendo da maior ou menor disposição de mobilidade de cada entrevistado. Além disso, pelo critério de escolha da pesquisa (pessoas em postos de gestão) deve ser reconhecido que os entrevistados representam o grupo que transpôs as barreiras apresentadas pelo contexto por suas ações individuais. Já aqueles que não conseguiram chegar a esse posto podem ter sido limitados por esses novos obstáculos.

Através do conjunto de análises, foi possível estabelecer quatro contribuições teóricas importantes que a utilização do método de história de vida possibilitou para se avançar nas discussões sobre carreira. A primeira delas foi a análise da carreira sob uma perspectiva situada sócio-historicamente. Por atuarem no mercado de trabalho em um período semelhante, todos os entrevistados relataram os impactos da abertura comercial e a chegada das novas tecnologias e modos de gestão nas organizações brasileiras a partir dos anos 1990. Mudanças como estas ocorrem de formas diferentes em cada país ou região e alteram as trajetórias profissionais, servindo como limitadores para aqueles que não conseguem se adaptar a elas e como um catalisador de desenvolvimento para os indivíduos que conseguem responder rapidamente às necessidades de mudança. Desta forma, o contexto sócio econômico emerge como uma barreira potencial no desenvolvimento profissional, alcançando de modos distintos cada mercado de trabalho (Rocha-de-Oliveira \& Piccinini, 2011).

Uma segunda contribuição do uso da história de vida no estudo de carreiras foi mostrar a existência de marcos de trajetória. No caso dos executivos brasileiros, o ingresso no ensino superior, a entrada no mercado de trabalho e a constituição da família, notadamente marcada no nascimento dos filhos, são momentos de tensão e reflexão que servem de base para novos direcionamentos na carreira. Estes marcos se relacionam com a influência de aspectos socioculturais, como no caso do ingresso no mercado de trabalho, que pode ocorrer mais cedo ou mais tarde, em virtude de peculiaridades culturais ou regionais.

A terceira contribuição foi a demonstração da força das relações familiares, tanto ascendentes quanto descendentes, nas decisões e direcionamento das carreiras: as lições dos pais, os valores da família ou da cultura local surgem como elementos centrais no direcionamento das escolhas dos entrevistados, evidenciando que, embora a carreira seja uma trajetória individual, ela é marcada pelos laços pessoais e sociais que se estabelecem ao redor dos sujeitos. 
Por fim, ilustrar a influência de uma cultura global tanto na formação e no aprendizado de idiomas quanto na disposição para a mobilidade na carreira dos pesquisados representou uma quarta contribuição do estudo propiciada pela análise das suas histórias de vida. No que se refere à mobilidade, as possibilidades profissionais alcançadas ou rechaçadas pelos entrevistados aparecem fortemente ligadas à disposição para a circulação entre diferentes cidades, tendo a vivência no exterior ou em um grande centro uma contribuição central no seu desenvolvimento profissional.

Estes quatro eixos de análise se articularam nas diferentes esferas da construção da carreira dos sujeitos entrevistados. Barreiras surgem em termos individuais em elementos adscritos como o gênero, mas também no desconhecimento de idiomas e na limitação para a mobilidade geográfica. Na esfera social, as barreiras se apresentam, em um primeiro nível, nos valores compartilhados com a família e nas expectativas de papéis sociais estabelecidos por seus grupos de referência. Numa esfera mais ampla, as mudanças econômicas e sociais do Brasil serviram de moldura para as trajetórias dos sujeitos pesquisados.

Essa forma de pesquisa permite a compreensão de ambos os antigos e os novos limites, como a crescente necessidade de mobilidade dos executivos brasileiros e os esforços feitos para a realização do processo de construção da ponte de centros periféricos aos grandes centros econômicos, bem como as limitações que representam para alguns profissionais. Ressalta-se, ainda, que as entrevistas de história de vida permitem que os entrevistados reflitam sobre suas experiências, permitindo-lhes tomar consciência das condições que limitam a sua liberdade, revelando novos pontos de vista que podem ajudá-los a assumir o controle de suas vidas e de suas carreiras, superando seus limites. Como limitações associadas à aplicação do método, destaca-se o tempo que essa abordagem de pesquisa requer, uma dificuldade importante, sobretudo se considerados os prazos exigidos pelos órgãos de fomento no Brasil. Ademais, no ambiente competitivo presente, a disponibilidade de tempo - escassa para a maioria dos profissionais - para a participação voluntária em duas ou três entrevistas, torna-se igualmente um obstáculo para o uso deste método de investigação. Afora isso, ao se buscar categorias temáticas semelhantes entre as falas de diferentes narradores, incorre-se no risco de inobservância de distintos significados expressos sob o mesmo tema e de desconsideração de respostas que se distanciem do padrão do restante do grupo. Recomenda-se, portanto, um cuidado com tais aspectos no processo de análise das entrevistas com histórias de vida.

\section{Referências}

Arthur, M. B. (2008). Examining contemporary careers: a call for interdisciplinary inquiry. Human Relations, 61(2), 163-186. doi: 10.1177/0018726707087783

Arthur, M. B. (2012). Examining contemporary careers: a call for interdisciplinary inquiry. In K. Inkson \& M. L. Savickas (Eds.), Career studies (pp. 321-342). London: Sage.

Arthur, M. B., Hall, D. T., \& Lawrence, B. S. (1989). Generating new directions in career theory. In M. B. Arthur, D. T. Hall, \& B. S. Lawrence (Eds.), Handbook of career theory (pp. 7-25). Cambridge: Cambridge University Press.

Arthur, M. B., \& Rousseau, D. M. (1996). The boundaryless career as a new employment principle. In M. B. Arthur \& D. M. Rousseau (Eds.), The boundaryless career (pp. 3-20). New York: Oxford University Press.

Atkinson, R. (2002). The life story interview. In J. F. Gubrium \& J. A. Holstein (Eds.), The handbook of interview research: context and method (pp. 121-141). London: Sage.

Bertaux, D. (1993). La perspective biografica: validez metodológica y sus potencialidades. In J. M. Marinas \& C. Santamarina (Eds.), La historia oral: métodos y experiencias (pp. 149-170). Madrid: Ediciones Debate. 
Bertaux, D., \& Kohli, M. (1984). The life history approach: a continental view. Annual Review of Sociology, 10, 215-237. doi: 10.1146/annurev.so.10.080184.001243

Biernacki, P., \& Waldorf, D. (1981). Snowball sampling: problems and techniques of chain referral sampling. Sociological Methods \& Research, 10(2), 141-163. doi: $10.1177 / 004912418101000205$

Chase, S. E. (2005). Narrative inquiry: multiple lenses, approaches, voices. In N. Denzin \& Y. Lincoln (Eds.), The sage handbook of qualitative research (3th ed., pp. 651-679). Thousand Oaks: Sage Publications.

Chudzikowski, K., \& Mayrhofer, W. (2011). In search of the blue flower? Grand social theories and career research: the case of Bourdieu's theory of practice. Human Relations, 64(1), 19-36. doi: $10.1177 / 0018726710384291$

Closs, L. Q., \& Antonello, C. S. (2011). O uso da história de vida para compreender processos de aprendizagem gerencial. Revista de Administração Mackenzie, 12(4), 44-74. doi: 10.1590/S167869712011000400003

Czarniawska, B. (2004). Narratives in social science research. London: Sage.

Delory-Momberger, C. (2012). Abordagens metodológicas na pesquisa biográfica. Revista Brasileira de Educação, 17(51), 523-740. doi: 10.1590/S1413-24782012000300002

Demartini, Z. (1988). Histórias de vida na abordagem de problemas educacionais. In O. Simson (Org.), Experimentos com histórias de vida: Itália-Brasil (pp. 44-105). São Paulo: Vértice.

Denzin, N. K. (1989). Interpretive biography. Newbury Park: SAGE Publications, Inc.

Fleury, A., \& Fleury, M. (2006). Aprendizagem e inovação organizacional: as experiências de Japão, Coréia e Brasil. São Paulo: Atlas.

Hall, D. T. (1996). Protean careers of the 21st century. Academy of Management Executive, 10(4), 8-16. doi: 10.5465/AME.1996.3145315

Hatch, J. A., \& Wisniewski, R. (1995). Life history and narrative: questions, issues and exemplary works. In J. Hatch \& R. Wisniewski (Eds.), Life history and narrative (pp. 113-135). London: RoutledgeFalmer.

Inkson, K., Gunz, H., Ganesh, S., \& Roper, J. (2012). Boundaryless careers: bringing back boundaries. Organization Studies, 33(3), 323-340. doi: 10.1177/0170840611435600

Inkson, K., \& Savickas, M. L. (2012). Introduction: fundamentals of career studies. In K. Inkson \& M. L. Savickas (Eds.), Career studies (pp. xxv-xxxiii). London: Sage.

Ituma, A., \& Simpson, R. (2009). The 'boundaryless' career and career boundaries: applying an institutionalist perspective to ICT workers in the context of Nigeria. Human Relations, 62(5), 727-761. doi: 10.1177/0018726709103456

Khapova, S. N., \& Arthur, M. B. (2011). Interdisciplinary approaches to contemporary career studies. Human Relations, 64(1), 3-17. doi: 10.1177/0018726710384294

Lawrence, B. S. (2011). Careers, social context and interdisciplinary thinking. Human Relations, 64(1), 59-84. doi: 10.1177/0018726710384293

Maclean, M., Harvey, C., \& Chia, R. (2012). Sensemaking, storytelling and the legitimization of elite business careers. Human Relations, 65(1), 17-40. doi: 10.1177/0018726711425616 
Moore, C., Gunz, H., \& Hall, T. D. (2007). Tracing de historical roots of career theory in management and organization studies. In H. Gunz \& M. Peiperl (Eds.), Handbook of career studies (pp. 1338). London: Sage.

Nicolini, A. (2003). Qual será o futuro das fábricas de administradores? Revista de Administração de Empresas, 43(2), 44-54. doi: 10.1590/S0034-75902003000200003

Nóvoa, A. (1995). Os professores e as histórias da sua vida. In A. Nóvoa (Org.), Vidas de professores (2a ed., pp. 11-30). Porto: Porto Editora.

Peticca-Harris, A., \& McKenna, S. (2013). Identity struggle, professional development and career: a case study of a human resource professional. Journal of Management Development, 32(8), 823835. doi: 10.1108/JMD-08-2011-0100

Riessman, C. K. (2005). Narrative analysis. In N. Kelly, C. Horrocks, K. Milnes, B. Roberts, \& D. Robinson (Eds.), Narrative, memory \& everyday life (pp. 1-7). Huddersfield: University of Huddersfield. Retrieved from http://eprints.hud.ac.uk/4920/2/Chapter_1__Catherine_Kohler_Riessman.pdf

Rocha-de-Oliveira, S., \& Piccinini, V. C. (2011). Mercado de trabalho: múltiplos (des)entendimentos. Revista de Administração Pública, 45(5), 1517-1538. doi: 10.1590/S0034-76122011000500012

Rocha-de-Oliveira, S., \& Piccinini, V. C. (2012). Uma análise sobre a inserção profissional de estudantes de administração no Brasil. Revista de Administração Mackenzie, 13(2), 44-75. doi: $10.1590 /$ S1678-69712012000200003

Sheftel, A., \& Zembrzycki, S. (2010). Only human: a reflection on the ethical and methodological challenges of working with "difficult" stories. The Oral History Review, 37(2), 191-214. doi: 10.1093/ohr/ohq050

Smith, J. M. (2012). Reflections on using life history to investigate women teachers' aspirations and career decisions. Qualitative Research, 12(4), 486-503. doi: 10.1177/1468794111433090

Spink, M. J., \& Lima, H. (2000). Práticas discursivas e produção de sentidos no cotidiano: aproximações teóricas e metodológicas. São Paulo: Cortez.

Sullivan, S. E., \& Baruch, Y. (2009). Advances in career theory and research: a critical review and agenda for future exploration. Journal of Management, 35(6), 1542-1571. doi: $10.1177 / 0149206309350082$

Van Maanen, J. (2015). The present of things past: ethnography and career studies. Human Relations, 68(1), 35-53. doi: 10.1177/0018726714552287

Xing, Y., \& Sims, D. (2012). Leadership, daoist wu wei and reflexivity: flow, self-protection and excuse in Chinese bank managers' leadership practice. Management Learning, 43(1), 97-112. doi: $10.1177 / 1350507611409659$

\title{
Dados dos Autores
}

\author{
Lisiane Quadrado Closs \\ Rua Washington Luiz, 855, 90010-460, Porto Alegre, RS, Brasil: E-mail: lisiane.closs@ufrgs.br \\ Sidinei Rocha-de-Oliveira \\ Rua Washington Luiz, 855, 90010-460, Porto Alegre, RS, Brasil: E-mail: sroliveira@ea.ufrgs.br
}

